\title{
INFLUENCE OF CARBON SOURCES ON $\alpha$-AMYLASE PRODUCTION BY BREVIBACILLUS sp. UNDER SUBMERGED FERMENTATION
}

\author{
K.Suribabu ${ }^{1}$, T.Lalitha Govardhan ${ }^{2}$, K.P.J Hemalatha ${ }^{3}$ \\ ${ }^{1,2}$ Assistant Professor, PG Department of Microbiology and Research Centre, Dr.Lankapalli Bullayya Post-graduate \\ College, Andhra Pradesh, India, Visakhapatnam-530 013 \\ ${ }^{3}$ Professor, Department Microbiology, Andhra University, Andhra Pradesh, India, Visakhapatnam-530 003
}

\begin{abstract}
Numerous marine microorganisms secrete enzymes which can provide new insights and understanding of enzymes. Marine microorganisms have been attracting more attention as source for novel enzymes. Secondary screening is strictly essential in any systematic screening programme which helps in detection of useful bacteria in fermentation processes. Secondary screening also provides information pertaining to the effect of different components of the medium. This is valuable in designing the medium that may be attractive as far as economic consideration is concerned. Natural carbon source, Saccharum officinarum (5\%) produced maximum $\alpha$-amylase while Triticum vulgare (4\%) produced very low $\alpha$-amylase. Synthetic carbon source when supplemented with maltose (1\%) and sucrose (4\%) regulated higher production of amylase. Starch (2\%), dextrose (3\%) and galactose (4\%) exhibited average effect on production whereas lactose (3\%) and mannitol (3\%) decreased production. The $\alpha$-amylase was found to have many applications in the field of starch processing, textile industry, improving shelf life of bread, ethanol production, sewage treatment and effluent treatment.
\end{abstract}

Keywords: Brevibacillus borostelensis R1, Saccharum officinarum, Triticum vulgare, maltose, sucrose

\section{INTRODUCTION}

Secondary screening is strictly essential in any systematic screening programme which helps in detection of useful bacteria in fermentation processes. It gives an idea about the economic position of the fermentation process involving the use of a newly discovered culture. Thus, one may have a comparative study of the process providing information regarding the enzyme yield potentials of different isolates. Secondary screening also provides information pertaining to the effect of different components of the medium. This is valuable in designing the medium that may be attractive as far as economic consideration is concerned. It determines the optimum conditions for production of enzyme associated with culture [1].

The production of $\alpha$-amylases by fermentation had been thoroughly investigated and shown to be affected by a variety of physicochemical factors, such as the composition of the growth medium, the type of strain, cell growth, methods of cultivation, inoculum concentration, time of incubation, $\mathrm{pH}$, temperature, salinity, carbon, nitrogen and mineral sources [25].

\subsection{Carbon Sources: Natural and Synthetic}

The addition of different carbon sources affects not only the mode of amylase production but also the rate of carbohydrates metabolized [6]. The addition of carbon source in the form of either monosaccharides or polysaccharides could influence the production of enzymes [7]. Fukumoto [8] initiated a series of studies for economically important alpha-amylase biosynthesis by supplementing various carbon sources. The activity of amylase is enhanced in the presence of different carbon sources such as Oryza sativa [9], Corn [10], Solanum tuberosam [11], Maltose [12], Xylose [13], Starch [14], Lactose [15], Galactose [16], Sucrose and Fructose [17], Glucose [18], Mannitol [19] and Cellulose [20].

Natural carbon sources do not have well defined concentration of the sugar. These sources contain various minerals which may also influence the $\alpha$-amylase production. Synthetic carbon sources are pure and with defined composition. These sources act as both energy and carbon source. High concentration of these sources may inhibit the production of $\alpha$ amylase. Simple sugars were used directly whereas the complex sugars were broken down to give simple sugars for utilization.

\section{MEDIA AND METERIALS}

Brevibacillus borostelensis R1 was cultured in Pikovskaya's medium with additional source of natural and synthetic carbon $(1-5 \% \mathrm{w} / \mathrm{v})$ separately by keeping the physical parameters (Incubation period 24hrs, inoculum size $2 \%, \mathrm{pH} 7.0$, temperature $370 \mathrm{C}$ and salinity $1 \%$ ) constant. Samples were incubated in orbital shaking incubator (120rpm) for $24 \mathrm{hrs}$. 
Natural sources include sagu (Metroxylon sago), wheat flour (Triticum vulgare), rice flour (Oryza sativa), maidha (Triticum vulgare), corn flour (Zea mays), ragi flour (Elusine coracana), jaggary (Saccharum officinarum), barley (Hardeum vulgare), potato (Solanum tuberosam) and chema (Colacashia esculenta). Synthetic sources include maltose (Himedia), xylose (Merck), starch (Merck), lactose (Merck), galactose (Merck), sucrose (Merck), fructose (Merck), dextrose (S.D.Fine-CHEM-Ltd.,), mannitol (Merck) and cellulose (Himedia).

Varying concentrations $(1,2,3,4$ and $5 \% \mathrm{w} / \mathrm{v})$ of ten natural and synthetic carbon sources were added to the $100 \mathrm{ml}$ of Pikovskaya's fermentation medium separately. As synthetic sources need no pretreatment they were added directly into the culture at varying concentrations. However, for natural sources of carbon, they were ground to powder with a mortar and pestle.

Two $\mathrm{ml}$ of inoculum of Brevibacillus borostelensis R1 was inoculated to the $100 \mathrm{ml}$ of production medium (Pikovskaya's Medium) and incubated in the orbital shaking incubator for 24hrs. After incubation, the medium was subjected to centrifugation at 5,000rpm for 15 minutes at room temperature (250C). The supernatant was collected in sterile test tube and the pellet was discarded. Supernatant $(0.5 \mathrm{ml})$ was used for the amylase assay by DNS method [21].Each concentration was assayed in triplicate sets and recorded for statistical analysis. One unit of enzyme activity was defined as the amount of enzyme that releases $1.0 \mathrm{mmol}$ of reducing sugar (maltose) per minute under the assay conditions.

\section{RESULTS}

Natural carbon sources utilized; Sagu (Metroxylon sago), Wheat flour (Triticum vulgare), Rice flour (Oryza sativa), Maidha (Triticum vulgare), Corn flour (Zeamays), Ragulu (Elusine coracana), Jaggary (Saccharum officinarum), Barley (Hardeum vulgare), Potato (Solanum tuberosam) and chema (Colacashia) were added separately to the production PK medium, at varying concentrations ranging from 1 to $5 \%$ maintaining constant physical parameters (Chart -1a-j). Ten synthetic carbon sources used; maltose, xylose, starch, lactose, galactose, sucrose, fructose, dextrose, mannitol and cellulose (Chart -2a-j).

The production of $\alpha$-amylase was estimated at different concentrations of carbon supplements and the highest production at optimum values were reported in the Table 1. The production was found to be higher in natural carbon supplement PK media as compared with synthetic carbon sources. However, the optimum production $7960.500 \pm 0.707$ $\mathrm{U} / \mathrm{ml}$ was found in natural carbon source of Jaggary (Saccharum officinarum) at 5\%.

Table 1 The highest production of $\alpha$-amylase at optimal concentrations of carbon sources (10): Natural and Synthetic

\begin{tabular}{|l|l|l|}
\hline Natural Carbon Sources & \% of Carbon Sources & Amylase activity (U/ml) \\
\hline Sago (Metroxylon sago) & 2 & $7080.50 \pm 0.50$ \\
\hline Wheat flour (Triticum vulgare) & 5 & $2261.00 \pm 1.41$ \\
\hline Rice flour (Oryza sativa) & 4 & $1980.50 \pm 0.70$ \\
\hline Maidha (Triticum vulgare) & 4 & $1341.75 \pm 0.35$ \\
\hline Corn flour (Zeamays) & 3 & $3661.00 \pm 1.414$ \\
\hline Ragulu (Elusine coracana) & 5 & $1901.000 \pm 1.414$ \\
\hline $\begin{array}{l}\text { Jaggary } \\
\text { (Saccharum officinarum) }\end{array}$ & 5 & $7960.500 \pm 0.707$ \\
\hline Barley (Hardeum vulgare) & 3 & $2480.500 \pm 0.707$ \\
\hline Solanum tuberosam (Potato) & 4 & $2420.500 \pm 0.707$ \\
\hline Chema (Colacashia) & 5 & $3000.500 \pm 0.707$ \\
\hline$\%$ of Synthetic Carbon Sources & \multicolumn{2}{|l|}{} \\
\hline Maltose & 1 & $3680.50 \pm 0.71$ \\
\hline Xylose & 5 & $2241 \pm 1.41$ \\
\hline Starch & 2 & $2061.50 \pm 2.12$ \\
\hline Lactose & 3 & $1441.50 \pm 2.12$ \\
\hline Galactose & 4 & $2361.00 \pm 1.41$ \\
\hline Sucrose & 4 & $2820.75 \pm 1.06$ \\
\hline Fructose & 4 & $4321 \pm 1.41$ \\
\hline Dextrose & 3 & $2161 \pm 1.41$ \\
\hline Mannitol & 3 & $1280.50 \pm 0.70$ \\
\hline Cellulose & 1 & $2721.00 \pm 1.41$ \\
\hline & & \\
\hline
\end{tabular}




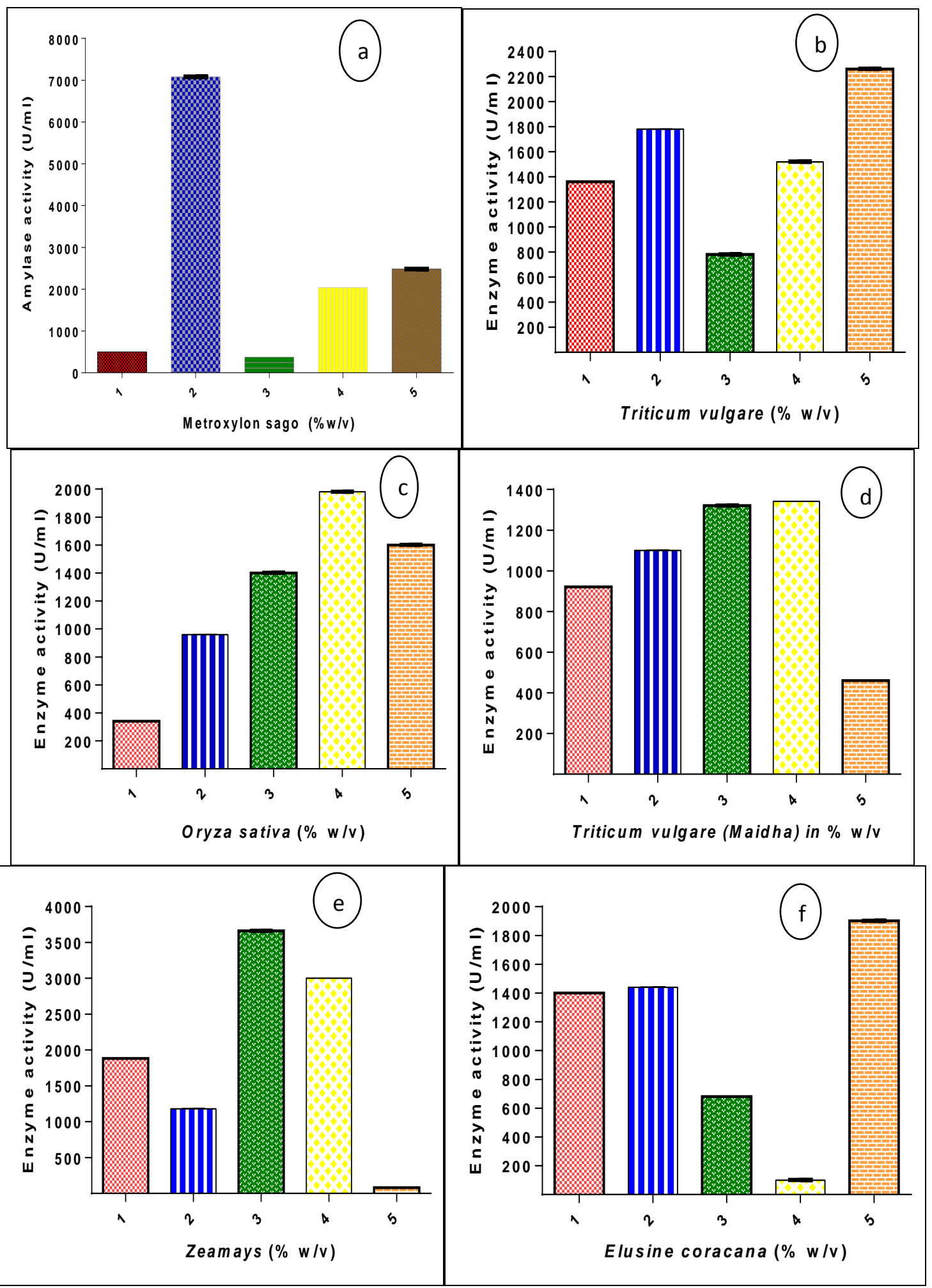

Chart -1: a-f. Effect of different concentrations of natural carbon sources on the production of $\alpha$-amylase by B. borstelensis R1 at different concentrations: a, Metroxylon sago; b, Triticum vulgare; c, Oryza sativa; d, Triticum vulgare; e, Zeamays and f, Elusine coracana. 


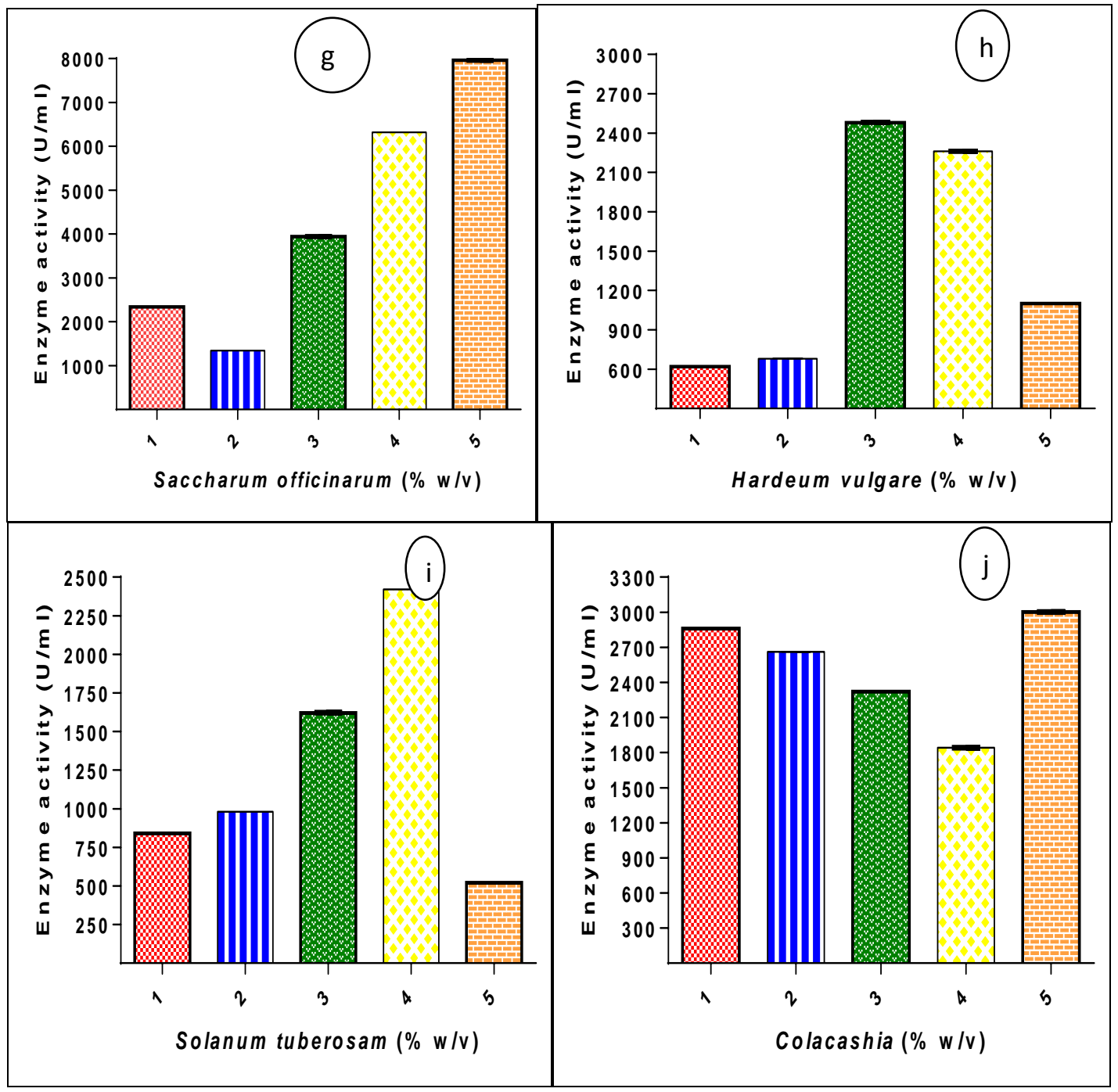

Chart -1: g-j. Effect of different concentrations of natural carbon sources on the production of $\alpha$-amylase by B. borstelensis R1 at different concentrations: g, Saccharum officinarum; h, Hardeum vulgare; I, Solanum tuberosam and j, Colacashia.

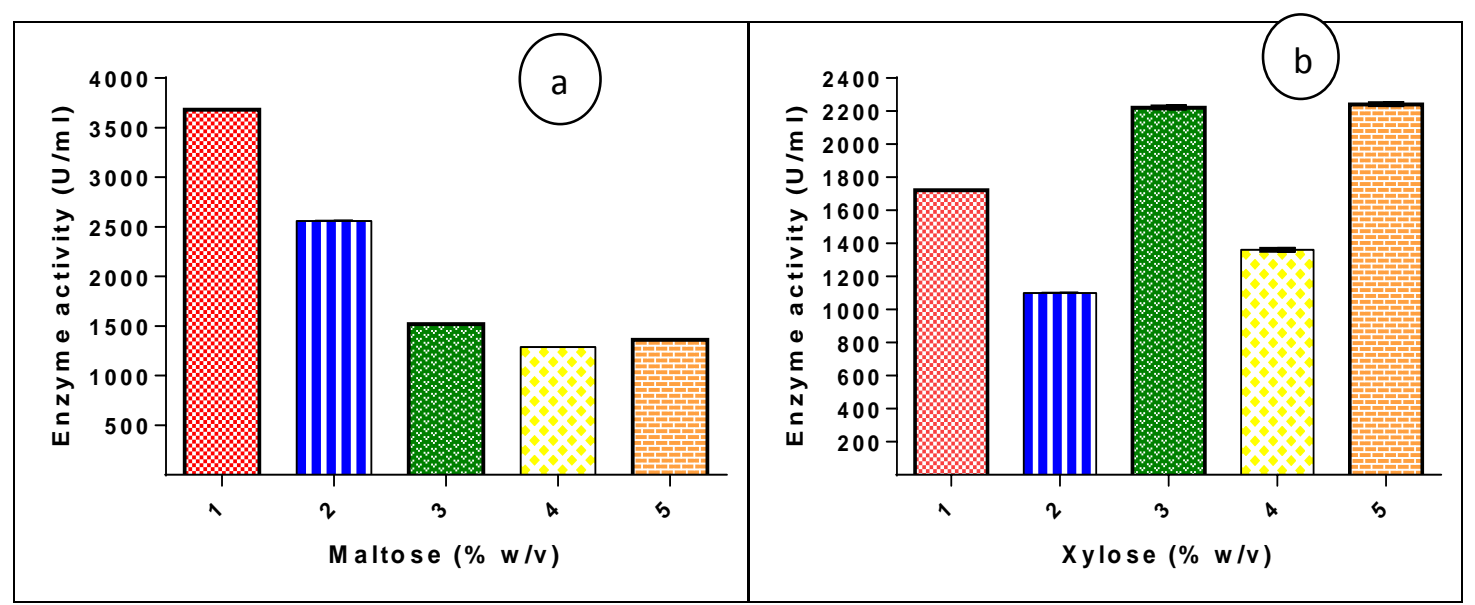




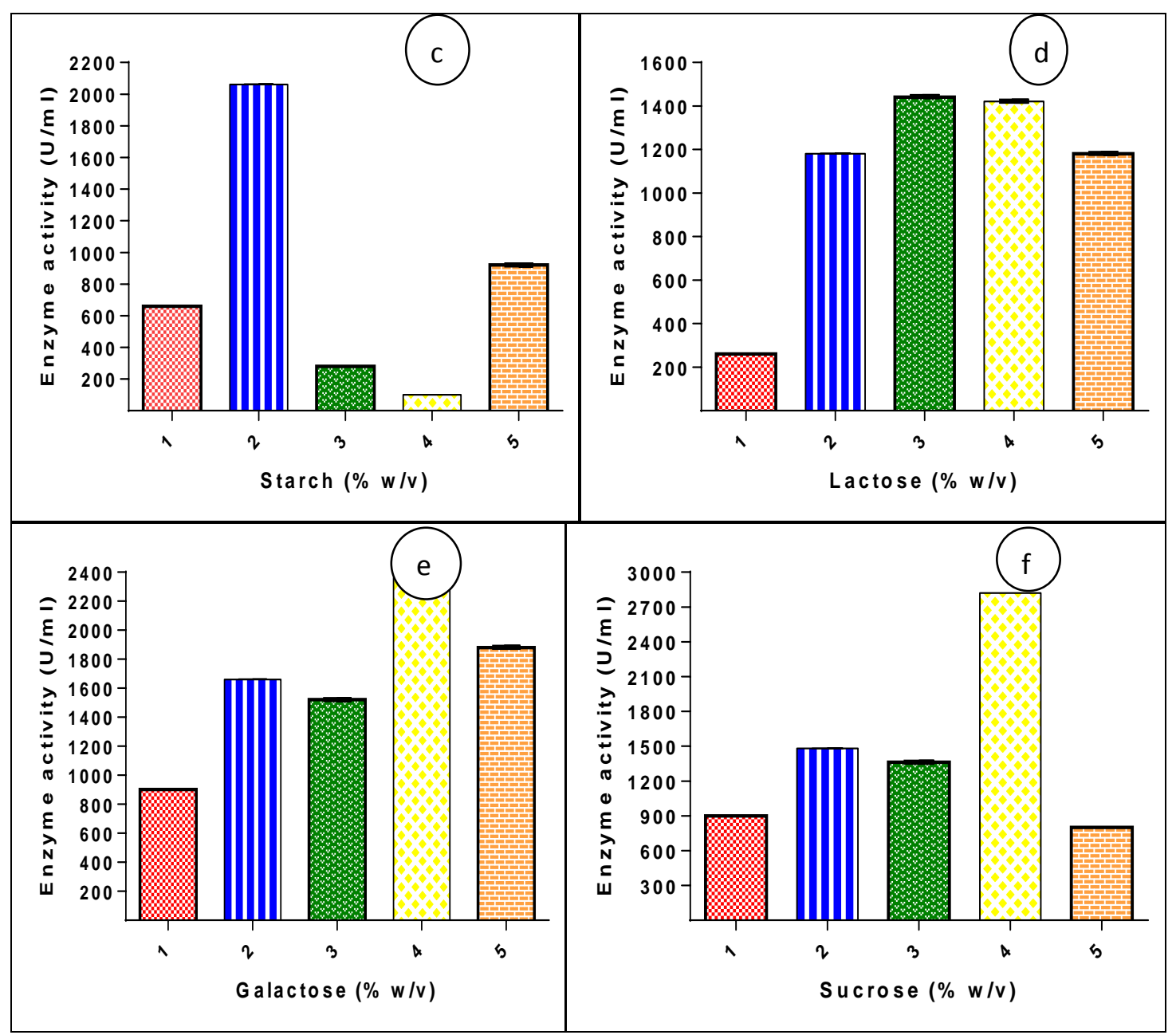

Chart -2: a-f. Effect of different concentrations of synthetic carbon sources on the production of $\alpha$-amylase by B. borstelensis R1: a, Maltose; b, Xylose; c, Starch; d, Lactose; e, Galactose and f, Sucrose.

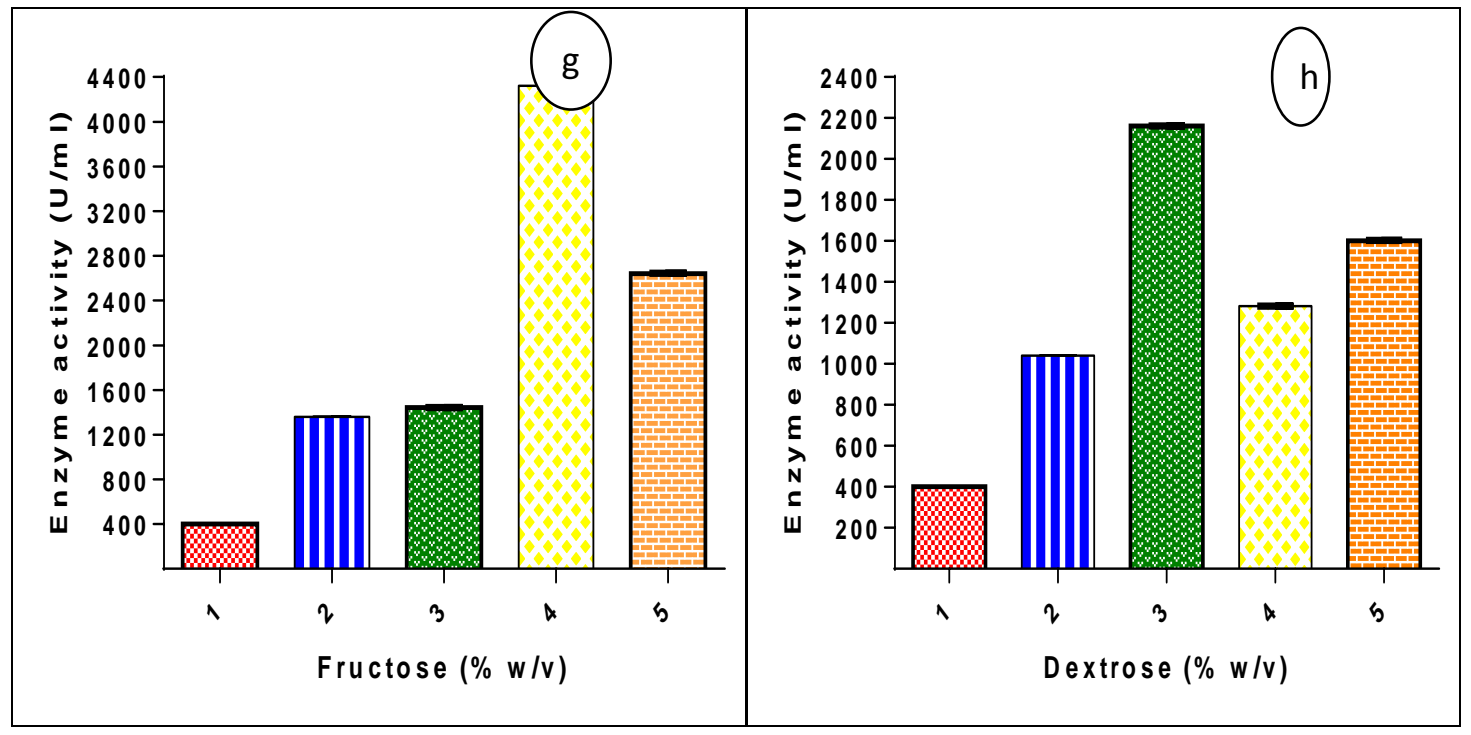




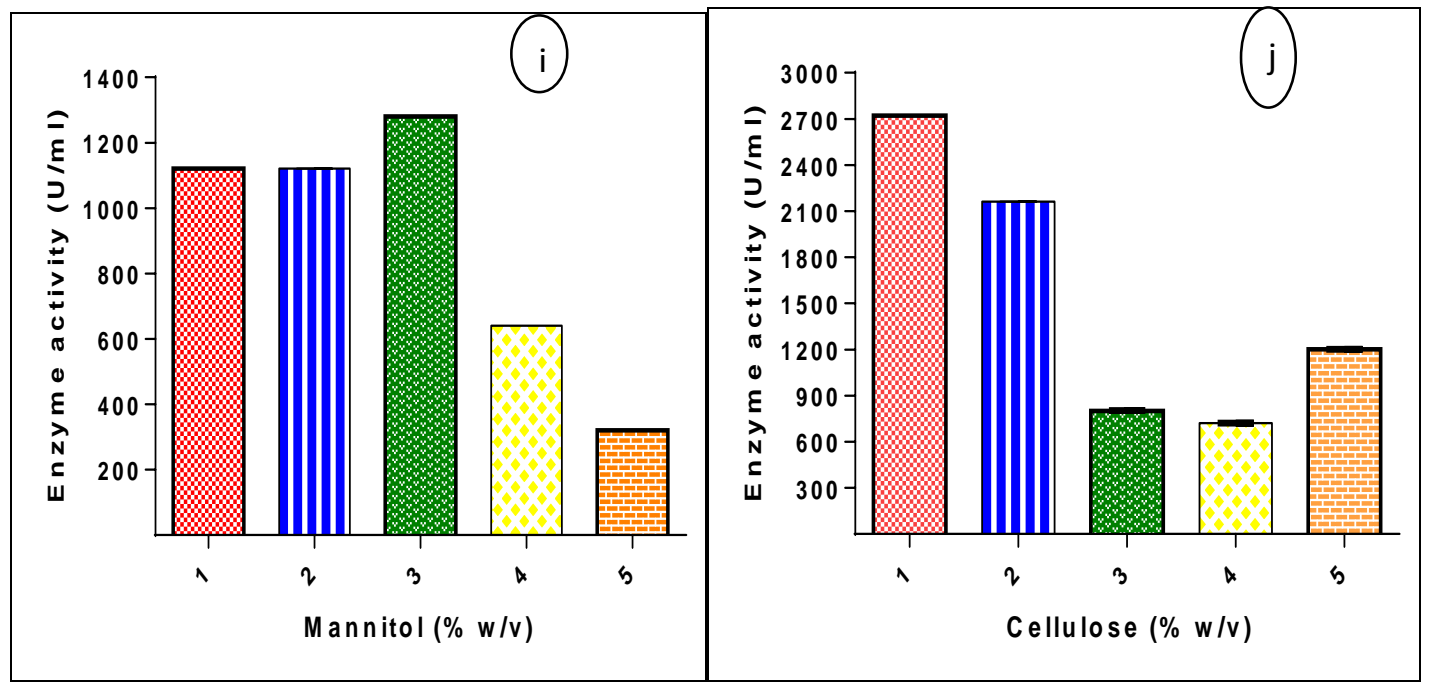

Chart -2: g-j. Effect of different concentrations of synthetic carbon sources on the production of $\alpha$-amylase by B. borstelensis R1: g, Fructose; h, Dextrose; i, Mannitol and j, Cellulose.

\section{DISCUSSIONS}

The production of $\alpha$-amylase was found to be highest in natural carbon supplement PK medium than synthetic carbon sources. The optimum production was found in natural additive of Saccharum officinarum (5\%) when compared with other sources. In Triticum vulgare (4\%) the production was the least. The production of amylase was found to be maximum in B.borostelensis $\mathrm{R} 1$ by the addition of $2 \%$ Metroxylon sago as reported by Yang \& Liu [22]. Triticum vulgare add-on in optimized production with Pencillium citrinum HBF62 was reported by Djekrif-Dakhmouche et al., [23].

In the synthetic carbon source supplement maltose (1\%) and sucrose $(4 \%)$ showed apex production of amylase, starch $(2 \%)$, dextrose $(3 \%)$ and galactose $(4 \%)$ exhibited moderate effect on production whereas lactose (3\%) and mannitol (3\%) demonstrated production depletion. Narang \& Satyanarayana [24] reported maltose as a provoking additive in some Bacillus sps. Different concentrations of maltose was reported by (1\%) $[25,26], 0.5 \%$ [27]. In contrast maltose suppressed the production of $\alpha$-amylase in Bacillus coagulans [28]. Sucrose as stimulant was described by Babu and Satyanarayana [29]. Starch in Bacillus sp. was found to be better augment to enhance amylase production as inquire into by Sodhi et al., [30]. Starch supplement $(2 \%)$ in PK medium gave maximum production in our studies. Similar findings were observed by Aditi et al., [31]. Dextrose exhibited enhanced amylase production by Bacillus sp. in the circulate of Narang \& Satyanarayana [24].Optimal production of amylase in different concentrations of dextrose $0.075 \%$ and $1.0 \%$ was examined by Salva \& Moraes [32] and Lin et al., [33] respectively. Lactose in Bacillus sp. was found to be enhancing the production as investigated by Hillier et al., [34]. Lactose (3\%) in PK medium has produced maximum production. In close relation with our studies Arunava et al., [35] and Hamilton et al., [36] reported lactose $2 \%$ and $4 \%$ respectively. Carlsen \& Nielsen [37] had showed accelerating effect of mannitol in the amylase production in Aspergillus oryzae.

\section{CONCLUSIONS}

Natural carbon source Saccharum officinarum (5\%) produced maximum $\alpha$-amylase while Triticum vulgare (4\%) produced very low $\alpha$-amylase. Synthetic carbon source when supplemented with maltose $(1 \%)$ and sucrose $(4 \%)$ regulated higher production of amylase. Starch (2\%), dextrose (3\%) and galactose $(4 \%)$ exhibited average effect on production whereas lactose $(3 \%)$ and mannitol $(3 \%)$ decreased production.

\section{ACKNOWLEDGEMENTS}

We thank Management of Dr.Lankapalli Bullayya College, Visakhapatnam for the financial support and facilities provided to make this work possible.

\section{REFERENCES}

[1]. Wulf Crueger and Anneliese Crueer (2004) A textbook of Industrial Microbiology, Second edition. Panima Publishing Corporation, 1-121.

[2]. Kumar N and Das D (2000) Production and purification of alpha-amylase from hydrogen producing Enterobacter cloacae IIT-BT 08. Biopro. Eng. 23: 205-208.

[3]. Mcvey F (2002) Alpha-amylase production using Bacillus sps. PER Review, 99-106.

[4]. Haq I, Ashraf H, Rani S and Qadeer M A (2002) Biosynthesis of alpha amylase by chemically treated mutant of Bacillus subtilis GCBU-20, Pak. J. Biol. Sci. 2: 73-75. 
[5]. Haq I, Shamim N, Ashraf H, Ali S and Qadeer MA(2005) Effect of surfactants on the biosynthesis of alpha-amylase by Bacillus subtilis GCBM-25. Pak.J.Bot.37: 373-379.

[6]. Abdullah R, Ashraf H and Haq I (2003) Optimization and kinetic analysis of carbon sources on the production of alpha amylase by Saccharomyces cerevisiae. J.Food Technology 1:187-190.

[7]. Sudharhsan S, Senthilkumar S and Ranjith K (2007) Physical and nutritional factors affecting the production of amylase from species of Bacillus isolated from spoiled food waste Afr. J. Biotechnol. 6: 430-435.

[8]. Fukumoto J (1943) Studies on the production of bacterial amylase. Isolation of bacteria secreening potent amylases and their distribution. J.of the Agri.Chem.Soc of Japan 19:487503.

[9]. Haq I, Shamim N, Ashraf H, Ali S and Qadeer MA(2005) Effect of surfactants on the biosynthesis of alpha-amylase by Bacillus subtilis GCBM-25. Pak. J. Bot. 37: 373-379.

[10]. Kunamneni A and Singh S (2005) Response surface optimization of enzymatic hydrolysis of maize starch for higher glucose production. Biochem. Eng. J. 27:179-190.

[11]. Goyal N, Gupta JK and Soni SK (2005) A novel raw starch digesting thermostable $\alpha$ - amylase from Bacillus sp. I-3 and its use in the direct hydrolysis of raw potato starch. Enz.Microb. Technol. 37: 723-734.

[12]. Gomes I, Gomes J and Steiner W (2003) Highly thermostable amylase and pullulanase of the extreme thermophilic eubacterium Rhodothermus marinus: Production and partial characterization. Biores. Techno. 90: 207-214.

[13]. Carlsen M and Nielsen J (2001) Influence of carbon source on $\alpha$-amylase production by Aspergillus oryzae.Appl. Microb. Biotechnol. 57:346-349.

[14]. Santos EO and Martins MLL (2003) Effect of the Medium Composition on Formation of Amylase by Bacillus sp. J. Braz. Arch. Biol. and Technol. 46: 129-134.

[15]. Narang S and Satyanarayana T (2001) Thermostable $\alpha$ amylase production by an extreme thermophile Bacillus therooleovorans. Lett. Appl. Microbiol. 32: 31-35.

[16]. Chandra AK, Medda S and Bhadra AK (1980) Production of extracellular thermostable $\alpha$-amylase by Bacillus licheniformis, J. Ferment. Technol. 58: 1-10.

[17]. Babu KR and Satyanarayana T (1993) Parametric optimization for extracellular alpha amylase production by thermophilic Bacillus coagulans B49. Folia Microbiol.38: 7780.

[18]. Coronado MJ, Vargas C, Hofemeister J, Ventosa A and Nieto JJ (2000) Production and biochemical characterization of an $\alpha$-amylase from the moderate halophile Halomonas meridiana. FEMS Microb. Letters 183: 67-71.

[19]. Carlsen M and Nielsen J (2001) Influence of carbon source on $\alpha$-amylase production by Aspergillus oryzae.Appl. Microb. Biotechnol. 57:346-349.

[20]. Gupta A, Gupta VK and Modi DR (2008) Production and characterization of $\alpha$-amylase from Aspergillus niger. Biotechnology 7: 551-556.
[21]. Miller GL (1959) Use of Dinitro salicylic acid reagent for determination of reducing sugar. Analy. Chem. 31: 426 429.

[22]. Yang C and Liu W (2004) Purification and properties of a maltotriose-producing $\alpha$-amylase from Thermobifida fusca. Enz. Microbial. Technol. 35: 254-260.

[23]. Djekrif-Dakhmouche S, Gheribi-Aoulmi Z, Meraihi Z and Bennamoun L (2005) Application of a statistical design to the optimization of culture medium for $\alpha$-amylase production by Aspergillus niger ATCC 16404 grown on orange waste powder, J. Food Eng. 73: 190-197.

[24]. Narang S and Satyanarayana T (2001) Thermostable $\alpha$ amylase production by an extreme thermophile Bacillus therooleovorans. Lett. Appl. Microbiol. 32: 31-35.

[25]. Adams MWW, Holden JF, Menon AL, Schut GJ, Grunden AM, Hou C, Hutchins AM, Jenney FE Jr, Kim C, Ma K, Pan G, Roy R, Sapra R, Story SV and Verhagen MFJM (2001) Key Role for Sulfur in Peptide Metabolism and in Regulation of Three Hydrogenases in the Hyperthermophilic Archaeon Pyrococcus furiosus J. Bacteriol. 2: 716-724.

[26]. Schut GJ, Brehm SD, Datta S and Adams MWW (2003). Whole-genome DNA microarray analysis of a hyperthermophile and an archaeon: Pyrococcus furiosus grown on carbohydrates or peptides. J. of Bacterio. 185: 39353947.

[27]. Tanyildizi MS, Ozer D and Elibol M (2005) Optimization of $\alpha$-amylase production by Bacillus sp. using response surface methodology. Proc. Biochem. 40: 22912296.

[28]. Deutch CE (2002) Characterization of a salt-tolerant extracellular $\alpha$-amylase from Bacillus dipsosauri. Lett Appl. Microbiol. 35: 78-84.

[29]. Babu KR and Satyanarayana T (1993) Parametric optimization for extracellular alpha amylase production by thermophilic Bacillus coagulans B49. Folia Microbiol. 38: 7780.

[30]. Sodhi HK, Sharma K, Gupta JK, and Soni SK (2005) Production of a thermostable $\alpha$-amylase from Bacillus sp. PS7 by solid state fermentation and its synergistic use in the hydrolysis of malt starch for alcohol production. Proc. Biochem. 40: 525-534.

[31]. Aditi A, Boora KS and Chaudhary K (2004) Production of extracellular $\alpha$-amylase by thermophilic Bacillus sp. Asian J. Microbiol. Biotechnol. Environ. Sci. 6: 391-394.

[32]. Salva TJG and Moraes IO (1995) Amylases purification and different sources sub categories of amylase production Rev. Microbiol. 26: 46.

[33]. Lin LL, Chyau CC and Hsu WH (1998) Production and properties of a raw-starch-degrading amylase from thermofilic and alkaliphilic Bacillus sp. TS-23. Biotech. Appl. Biochem. 28: 61-68.

[34]. Hillier P, Wase DAJ and Emery AN (1996) Production of alpha-amylase by Bacillus amyloliquefaciens in batch and continuous culture using a defined synthetic medium. Biotechnol.Lett. 18:795-800. 
[35]. Arunava B, Pal SC and Sen SK (1993) Alpha amylase production in lactose medium by Bacillus circulanse. J. Microbiologia. 9: 142-148.

[36]. Hamilton LM, Kelly CT and Fogarty WM (1999) Production and properties of the raw-starch-digesting $\alpha$ amylase of Bacillus sp. IMD- 435. Process Biochemistry 35: $27-31$.

[37]. Carlsen $M$ and Nielsen $J$ (2001) Influence of carbon source on $\alpha$-amylase production by Aspergillus oryzae.Appl. Microb. Biotechnol. 57:346-349.

\section{BIOGRAPHIES}

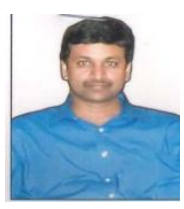

Dr. K. Suribabu, Assistant Professor, PG Department of Microbiology and Research Centre, Dr.Lankapalli Bullayya PG College, Andhra Pradesh, India,Visakhapatnam-530 013,ksuribabu_sda@yahoo.com

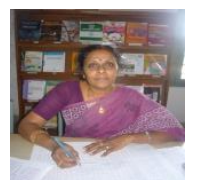

Dr. T.Lalitha Govardhan, Associate Professor, PG Department of Microbiology and Research Centre, Dr.Lankapalli Bullayya Post-graduate College, Andhra Pradesh, India, Visakhapatnam-530 013, drlalithagovardhan@gmail.com

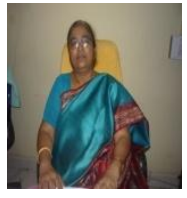

Dr. K.P.J Hemalatha, Professor, Department Microbiology College of Science and Technology, Andhra University, Visakhapatnam- 530 003, Andhra Pradesh, India, hemalathakpj@gmail.com 